OPEN ACCESS

Edited by:

Hongyin Zhang,

Jiangsu University, China

Reviewed by:

Jon Y. Takemoto,

Utah State University, United States

Prabuddha Dey,

Rutgers University - The State

University of New Jersey,

United States

Hai-Lei Wei,

Chinese Academy of Agricultural

Sciences, China

*Correspondence.

Kaifang Zeng

zengkaifang@hotmail.com

Specialty section:

This article was submitted to

Food Microbiology,

a section of the journal

Frontiers in Microbiology

Received: 05 June 2018 Accepted: 25 September 2018 Published: 10 October 2018

Citation:

Wang W, Liu S, Deng L, Ming J, Yao S and Zeng K (2018) Control of Citrus Post-harvest Green Molds,

Blue Molds, and Sour Rot by

the Cecropin A-Melittin Hybrid

Peptide BP21.

Front. Microbiol. 9:2455.

doi: $10.3389 /$ fmicb.2018.02455

\section{Control of Citrus Post-harvest Green Molds, Blue Molds, and Sour Rot by the Cecropin A-Melittin Hybrid Peptide BP21}

\author{
Wenjun Wang ${ }^{1}$, Sha Liu' ${ }^{1}$, Lili Deng ${ }^{1,2}$, Jian Ming ${ }^{1,2}$, Shixiang Yao ${ }^{1,2}$ and Kaifang Zeng ${ }^{1,2 *}$ \\ ${ }^{1}$ College of Food Science, Southwest University, Chongqing, China, ${ }^{2}$ Research Center of Food Storage \& Logistics, \\ Southwest University, Chongqing, China
}

In this study, the activity of the cecropin A-melittin hybrid peptide BP21 (AcFKLFKKILKVL-NH$H_{2}$ ) in controlling of citrus post-harvest green and blue molds and sour rot and its involved mechanism was studied. The minimum inhibitory concentrations of BP21 against Penicillium digitatum, Penicillium italicum, and Geotrichum candidum were 8,8 , and $4 \mu \mathrm{mol} \mathrm{L}{ }^{-1}$, respectively. BP21 could inhibit the growth of mycelia, the scanning electron microscopy results clearly showed that the mycelia treated with BP21 shrank, formed a rough surface, became distorted and collapsed. Fluorescent staining with SYTOX Green (SG) indicated that BP21 could disintegrate membranes. Membrane permeability parameters, including extracellular conductivity, the leakage of potassium ions, and the release of cellular constituents, visibly increased as the BP21 concentration increased. Gross and irreversible damage to the cytoplasm and membranes was observed. There was a positive correlation between hemolytic activity and the concentration of BP21. These results suggest peptide BP21 could be used to control citrus post-harvest diseases.

Keywords: peptide BP21, post-harvest, citrus fruit, diseases control, mode of action

\section{INTRODUCTION}

Green mold, blue mold, and sour rot caused by Penicillium digitatum, Penicillium Italicum, and Geotrichum candidum (syn. Geotrichum citri-aurantii) are the most serious post-harvest fungal diseases. Sour rot cannot be inhibited by imazalil and thiabendazole, which are effective chemical fungicides against green mold and blue mold (Droby et al., 2002; Ismail and Zhang, 2004). The application of chemical fungicides has been restricted due to the concerns about pesticide residues, environmental pollution and pathogens resistance. It is urgent to search for effective, ecofriendly methods of diseases control to replace or reduce the use of harmful chemical fungicides (Schirra et al., 2011; Romanazzi et al., 2017).

Antimicrobial peptides (AMPs) as novel antibiotics are widely studied, it has been proposed their use to fight phytopathogens in agriculture, animal husbandry, post-harvest conservation, and the food industry (Jenssen et al., 2006; Keymanesh et al., 2009; Ciociola et al., 2016). The application of peptides in the control of fruit and vegetable diseases is gaining attention. An increasing number of AMPs have been shown to control fruit and vegetable diseases. In previous research, PAF56 (GHRKKWFW) was shown to effectively control of fungi infection in citrus 
fruits (Wang et al., 2018). There are likely many AMPs yet to be discovered that can effectively control fruit and vegetable diseases.

Cecropins were first discovered in the hemolymph of the giant silk moth Hyalophora cecropia (Andreu et al., 1983), and they are some of the best known cationic AMPs, representing a family of highly basic $\alpha$-helical peptides. In particular, Cecropin A displays powerful lytic activity against bacteria but has no cytotoxic effects against eukaryotic cells. However, because many fruit and vegetable diseases are caused by fungi, certain natural AMPs should be modified with new sequences that confer improved antimicrobial and therapeutic properties (Chicharro et al., 2001; Alberola et al., 2004). In particular, certain peptides from the CECMEL11 library (LIPPSO-CIDSAV, University of Girona, Girona, Spain), which is composed of de novo designed and synthetically produced cecropin A-melittin hybrid linear undecapeptides, have been derived from the peptide Pep3 (WKLFKKILKVL-NH $_{2}$ ) and evaluated for Stemphylium vesicarium infection control in pears (Badosa et al., 2009). For example, BP15 (KKLFKKILKVL- $\mathrm{NH}_{2}$ ) inhibited S. vesicarium growth, produced morphological alterations to germ tubes and induced cell membrane disruption (Ferre et al., 2006; Puig et al., 2014, 2016). BP15 also could control the infection caused by $P$. digitatum on citrus fruit (Muñoz et al., 2007). In addition, BP21 (Ac-FKLFKKILKVL-NH N $_{2}$ ) was designed to inhibit the plant pathogenic fungi Fusarium oxysporum, Aspergillus niger, Rhizopus stolonifer, and Penicillium expansum. It has been shown that BP21 can effectively inhibit $P$. expansum in vitro and control the post-harvest decay caused by $P$. expansum in apples (Badosa et al., 2009). Penicillium species that affect the post-harvest of fruits further highlight the need to develop AMPs. We predicted that BP21 could control post-harvest diseases on citrus fruit as well. Cecropin A, melittin and their hybrids have been widely studied for their antibacterial mode of action (Makovitzki et al., 2007; Ferre et al., 2009), but the mechanisms that underlie their interactions with plant pathogenic filamentous fungi are still unclear.

The aim of the present study was to investigate the effects of the peptide BP21 in inhibiting $P$. digitatum, $P$. italicum, and $G$. candidum in vitro and in vivo, and the mode of action of BP21 was studied.

\section{MATERIALS AND METHODS}

\section{Antifungal Peptide and Fungal Strains}

Peptide BP21 (FKLFKKILKVL) was synthesized at $>90 \%$ purity from GenScript Corporation (Nanjing, China) by solidphase methods using $N$-(9-fluorenyl) methoxycarbonyl (Fmoc) chemistry. BP21 was acetylated at the $\mathrm{N}$ terminus (Ac) and amidated at the $\mathrm{C}$ terminus $\left(\mathrm{NH}_{2}\right)$. Stock solutions of peptides were prepared at $1 \mathrm{~m} \mathrm{~mol} \mathrm{~L}^{-1}$ in sterile ultrapure water and stored at $-40^{\circ} \mathrm{C}$.

The fungi ( $P$. digitatum, $P$. italicum, and $G$. candidum) used in this work were obtained from spoiled citrus fruits and identified. They were cultured on potato dextrose agar (PDA) that contained an infusion of $200 \mathrm{~g} \mathrm{~L}^{-1}$ potatoes, $20 \mathrm{~g} \mathrm{~L}^{-1}$ glucose, and $20 \mathrm{~g} \mathrm{~L}^{-1}$ agar at $25^{\circ} \mathrm{C}$. The spores from a 7 -day-old culture were collected, filtered, and adjusted to the suitable concentration with the aid of a hematocytometer (Jeong et al., 2016).

\section{Effects of the Fungal Growth in vitro}

The fungicidal activities of the peptide BP21 was determined by dose-response curves as previously described (López-García et al., 2002; Wang et al., 2018). BP21 was added to a final concentration of $0.25,0.5,1,2,4,8,16,32,64 \mu \mathrm{M}$, respectively. In all experiments, three replicates were prepared for each treatment. The growth of the fungi was determined by measuring $\mathrm{OD}_{600}$ using a Multiskan Spectrum microplate spectrophotometer (BioTek Instruments, Inc., United States) at $48 \mathrm{~h}$ after mixing with $\mathrm{BP} 21$. The minimum inhibitory concentration (MIC) of the peptide BP21 for three fungi was defined as the peptide BP21 concentration that completely inhibited growth in all the experiments carried out.

\section{Scanning Electron Microscopy (SEM)}

To determine the effect of BP21 on the mycelia morphology of the three fungi, a scanning electron microscopic (SEM) study was performed. The mycelia from 2-day-old culture were collected, washed, and then resuspended in sterilized distilled water. BP21 (10 or $100 \mu \mathrm{mol} \mathrm{L}{ }^{-1}$ ) was mixed into the suspensions for $48 \mathrm{~h}$, and controls without BP21 were tested similarly. The mycelia were collected and placed in vials containing 3.0\% (v/v) glutaraldehyde in $0.05 \mathrm{~mol} \mathrm{~L}^{-1}$ phosphate buffered saline $(\mathrm{pH}$ 6.8 ) at $4^{\circ} \mathrm{C}$. The mycelia were kept in this solution for $48 \mathrm{~h}$ for fixation and then washed with $0.05 \mathrm{~mol} \mathrm{~L}^{-1}$ phosphate buffered saline two times. The samples were dehydrated in an ethanol series $(30,50,70,85$ and $95 \%, \mathrm{v} / \mathrm{v})$ for $10 \mathrm{~min}$ in each alcohol dilution, ending with absolute ethanol twice. Then, the ethanol was replaced with tertiary butyl alcohol. After dehydration, the samples were dried with carbon dioxide. Finally, the specimens were sputter-coated with gold in an ion coater for $2 \mathrm{~min}$. All samples were viewed in a JEOL JSM-6510LV SEM (JEOL, Tokyo,

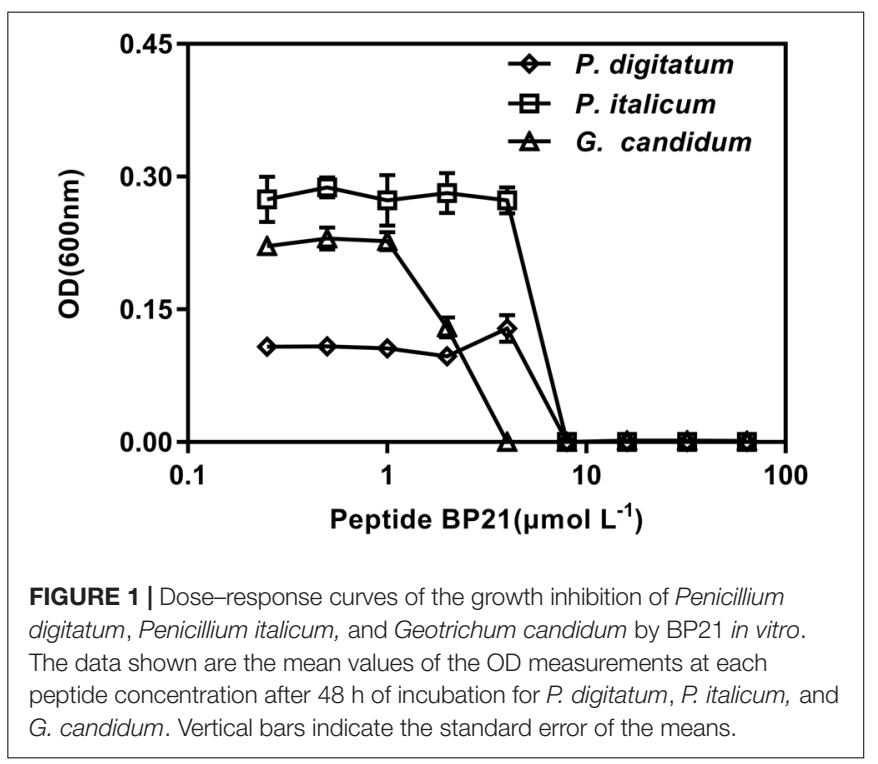



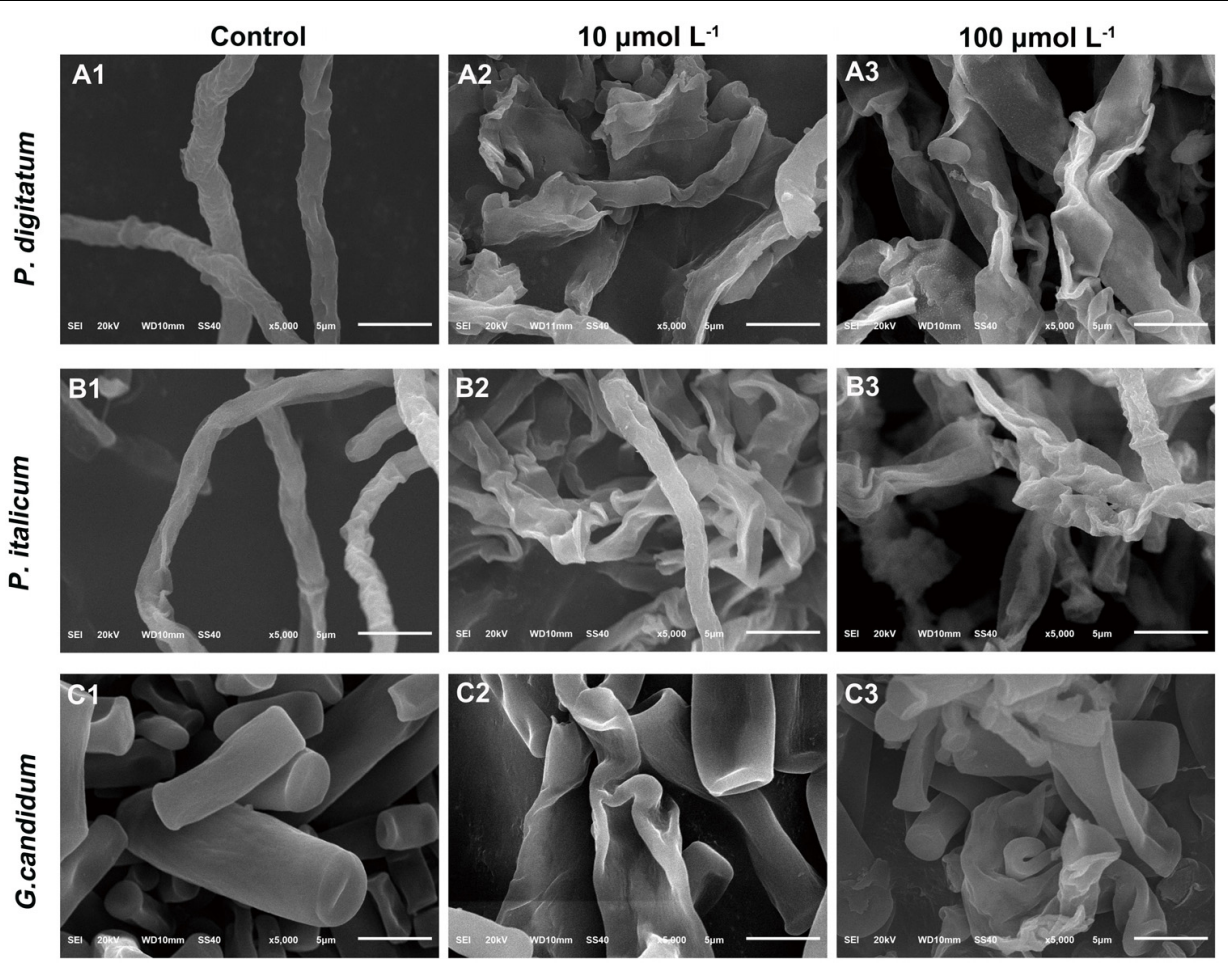

FIGURE 2 | Scanning electron microphotography (SEM) of $P$. digitatum (A), P. italicum (B), and G. candidum (C) mycelia treated with BP21. Mycelia were incubated in 5\% PDB without BP21 (A1-C1) or with BP21 at final concentrations of $10 \mu \mathrm{mol} \mathrm{L}^{-1}$ (A2-C2) or $100 \mu \mathrm{mol} \mathrm{L}-1$ (A3-C3). Bars $=5 \mu \mathrm{m}$.

Japan) operating at $25 \mathrm{kV}$ at $5000 \times$ magnification (Tao et al., 2014).

\section{Fluorescence Microscopy}

The mode of action of BP21 with the mycelia was characterized by the fluorescent dye SYTOX Green (SG) (Molecular Probes; Invitrogen, Corp, Carlsbad, CA, United States) as described previously (Puig et al., 2016; Wang et al., 2018). BP21 was used to each treatment groups to reach a final concentration of 10 or $100 \mu \mathrm{mol} \mathrm{L}{ }^{-1}$. After incubation with BP21, the fungal suspensions were stained with SG. Fluorescence was examined and photographed with an Eclipse TS100 epifluorescence microscope (Nikon Corporation, Japan) with FITC filter sets. Simultaneous brightfield images were captured as well.

\section{Measurement of Extracellular Conductivity, $\mathrm{K}^{+}$Efflux and Release of Cellular Constituents}

BP21 was used to each treatment groups to reach a final concentration of 10 or $100 \mu \mathrm{mol} \mathrm{L} \mathrm{L}^{-1}$. The extracellular conductivity of mycelia by using a DDS-307A conductivity meter (INESA, Shanghai, China) according to a previously described method (Wang et al., 2018), and controls without BP21 were tested similarly. Then, a previously described method was used to determine the amount of the potassium ions (Bajpai et al., 2013; Tao et al., 2014). The concentration of free potassium ions in the suspensions of $P$. digitatum, $P$. italicum, and G. candidum mycelia was measured at $0,3,6,9,12,24$, and $48 \mathrm{~h}$ of treatment. The extracellular potassium concentration were determined in the supernatant using flame atomic absorption spectroscopy (Shimadzu AA6300, Japan).

The release of cellular constituents into the supernatant was measured according to a method described previously (Paul et al., 2011) with minor modifications. The release of cellular constituents into the supernatant was measured using a wavelength of $260 \mathrm{~nm}$ from a Multiskan Spectrum microplate spectrophotometer. Fungi was incubated in an environmental shaking incubator for $48 \mathrm{~h}$, then the mycelia were collected and washed three times with phosphate buffered saline ( $\mathrm{pH} 7.0)$ and resuspended in buffered saline. BP21 (10 or $100 \mu \mathrm{mol} \mathrm{L} \mathrm{L}^{-1}$ ) was added to the suspensions, and controls without BP21 were tested similarly. The results were expressed in terms of the optical density of absorption at $260 \mathrm{~nm}$ at $0,3,6,9,12,24$, and $48 \mathrm{~h}$ of treatment.

\section{Fruit Decay Tests}

Experiments were carried out on freshly harvested navel oranges [Citrus sinensis (L.) Osbeck]. Fruit were harvested from a local orchard (Beibei, Chongqing). A previously described method was used in this experiment (Wang et al., 2018). Briefly, the fruit were surface-disinfected for $2 \mathrm{~min}$ in $2 \%$ sodium hypochlorite solution, washed and allowed to air dry. Citrus fruit were wounded ( $3 \mathrm{~mm}$ wide and $4 \mathrm{~mm}$ deep) by making punctures at two sites around the equator. The inocula contained $10^{4}$ $\mathrm{CFU} \mathrm{mL} \mathrm{m}^{-1}$ spores and peptide BP21 at $8 \mu \mathrm{mol} \mathrm{L}^{-1}$ in water. 


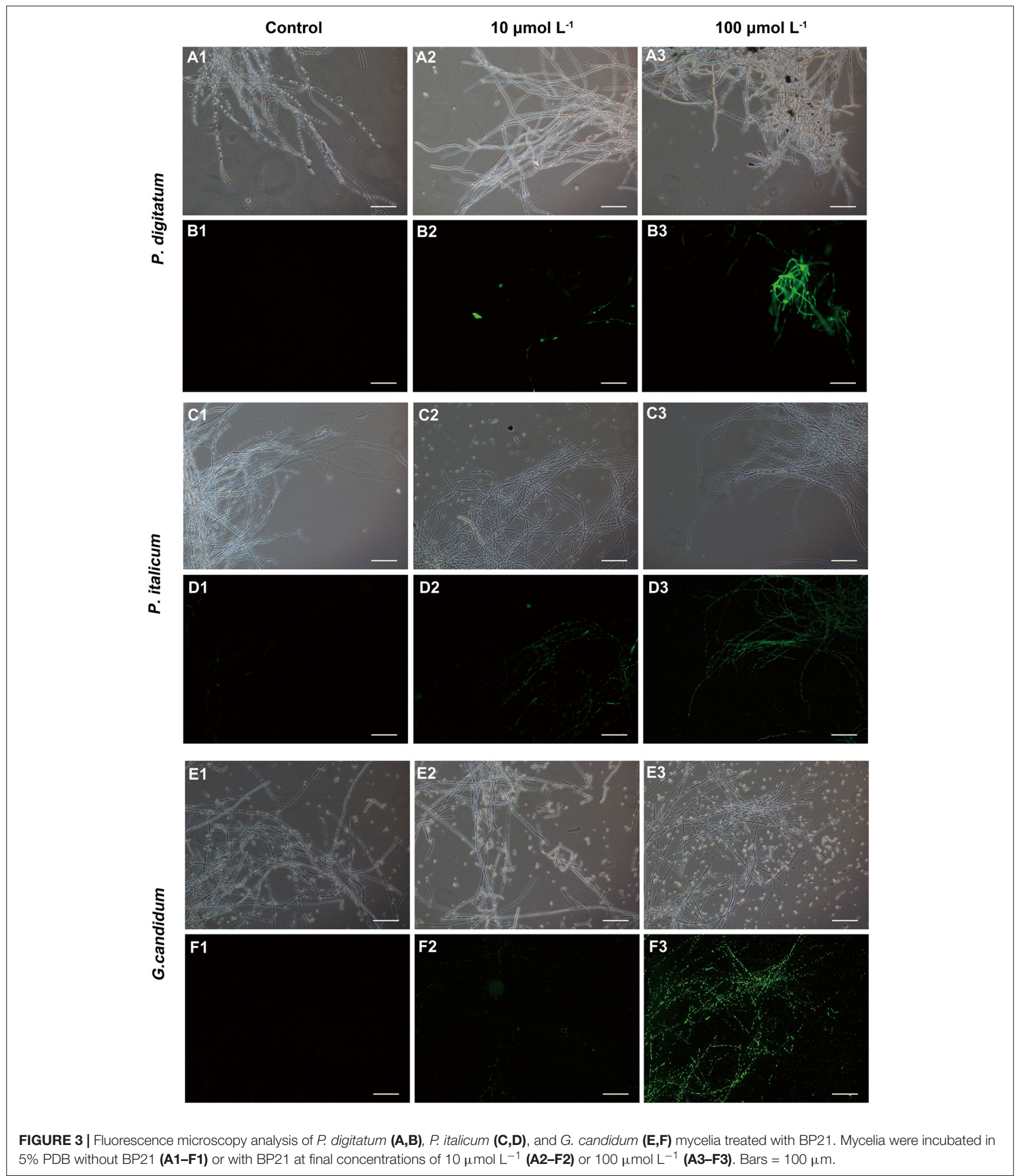

As described in Section "Results," two different times (A: 0 h; B: $16 \mathrm{~h}$ ) of incubation of conidia with BP21 prior to inoculation were evaluated. Citrus fruit inoculated with conidia alone as the controls. The disease incidence (DI) and the lesion diameter
(LD) was assessed daily. Three replicates (15 fruits per replicate, 2 wounds per fruit) were prepared for each treatment. The mean values \pm SD of the $\mathrm{DI}$ and $\mathrm{LD}$ for each treatment were calculated. 


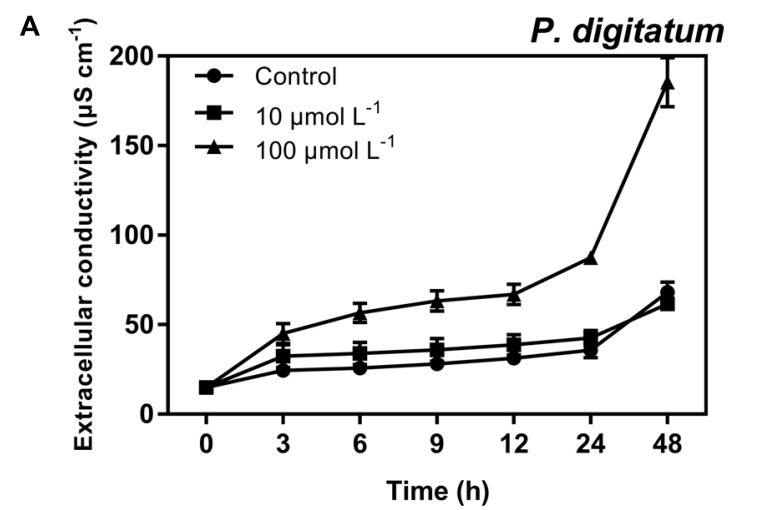

B

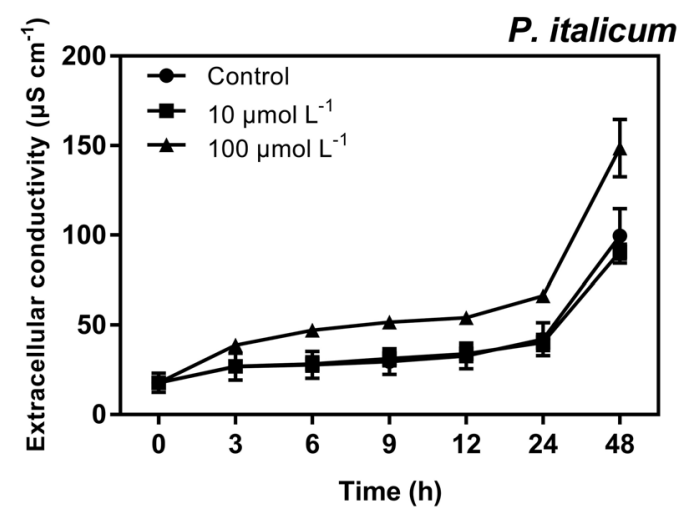

C

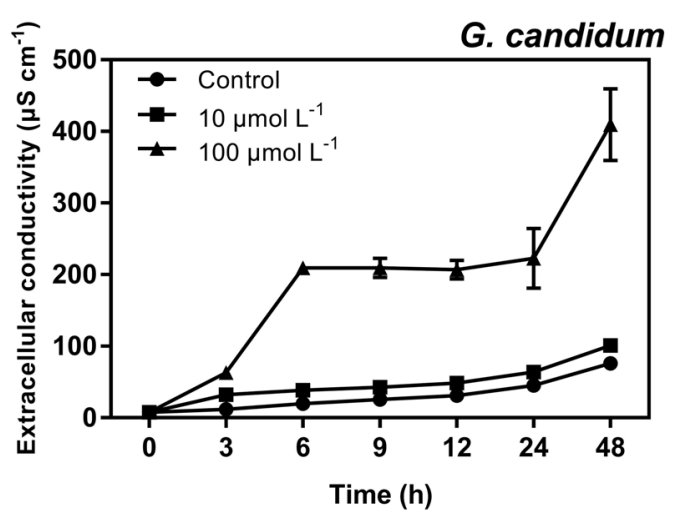

FIGURE 4 | Extracellular conductivity of P. digitatum (A), P. italicum (B), and G. candidum (C) mycelia treated with BP21. Mycelia were incubated in 10 or $100 \mu \mathrm{mol} \mathrm{L}{ }^{-1}$ or without BP21 (control) solutions. Vertical bars indicate the standard error of the means.

\section{Hemolytic Activity of BP21}

The hemolytic test was carried out by using $2 \%$ erythrocyte suspension, which was prepared from human blood according to the previous description (Muñoz et al., 2006) with partial modifications. No hemolysis and $100 \%$ hemolysis were determined for controls with normal saline (NS) and $0.1 \%$ Triton X-100, respectively. The AMPs BP21 (The final concentration was $8,16,32$, or $64 \mu \mathrm{mol} \mathrm{L}^{-1}$ ) was mixed with $2 \%$ red blood cells and incubated at $37^{\circ} \mathrm{C}$ for $1 \mathrm{~h}$. After diluted 600 times, commercial Prochloraz was mixed with erythrocyte suspension. The samples were centrifuged at
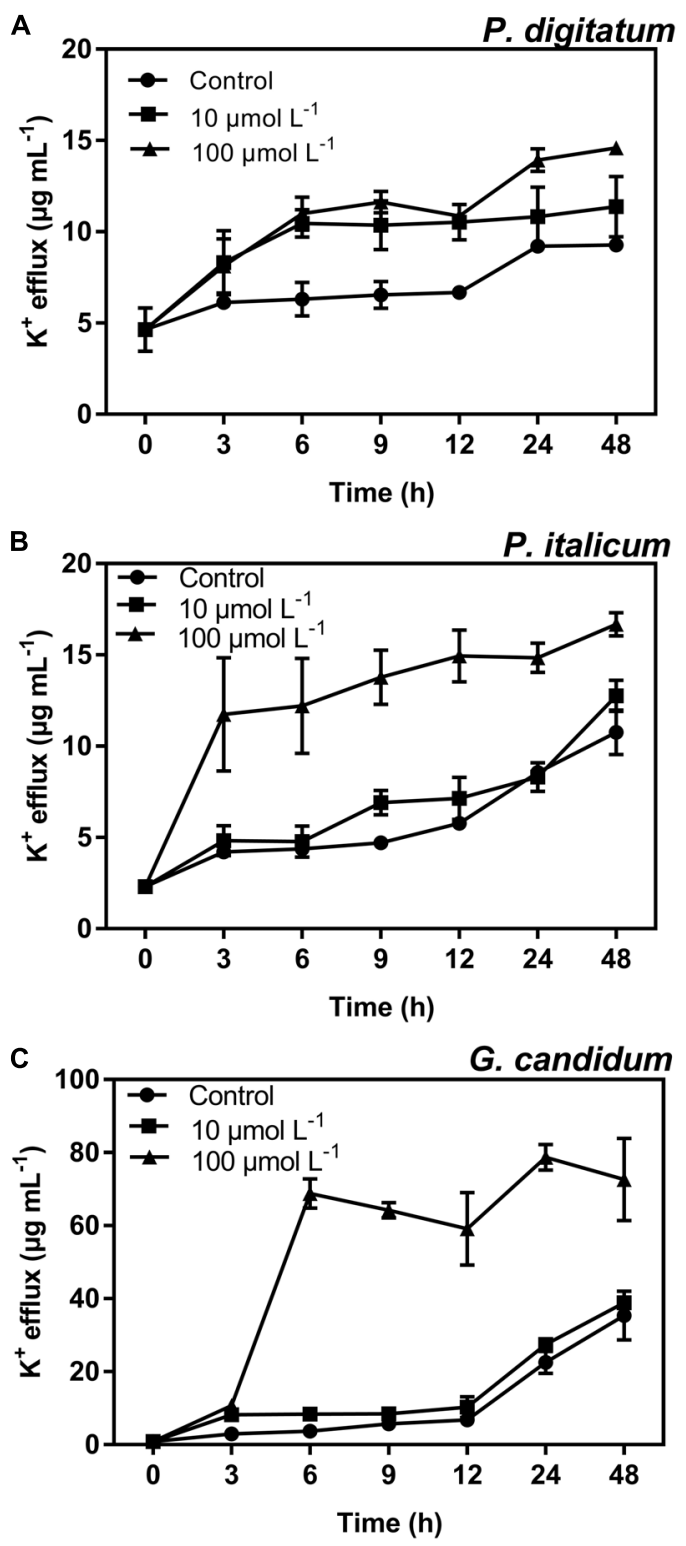

FIGURE $5 \mid \mathrm{K}^{+}$efflux of $P$. digitatum (A), P. italicum (B), and G. candidum (C) mycelia treated with BP21. Mycelia were incubated in 10 or $100 \mu \mathrm{mol} \mathrm{L}^{-1}$ or without BP21 (control) solutions. Vertical bars indicate the standard error of the means.

$1,000 \times g$ for $5 \mathrm{~min}$, and the supernatant was transferred to 96-well plates. Release of hemoglobin was determined by $\mathrm{OD}_{540}$, and the data were measured by a Multiskan Spectrum microplate spectrophotometer. The hemolytic activity of peptide was calculated as the percentage of total hemoglobin released compared with that released by incubation with $0.1 \%$ Triton $\mathrm{X}-100$.

\section{Statistical Analysis}

In the statistical analysis of the randomized complete block design, each treatment involved three replications, and the 

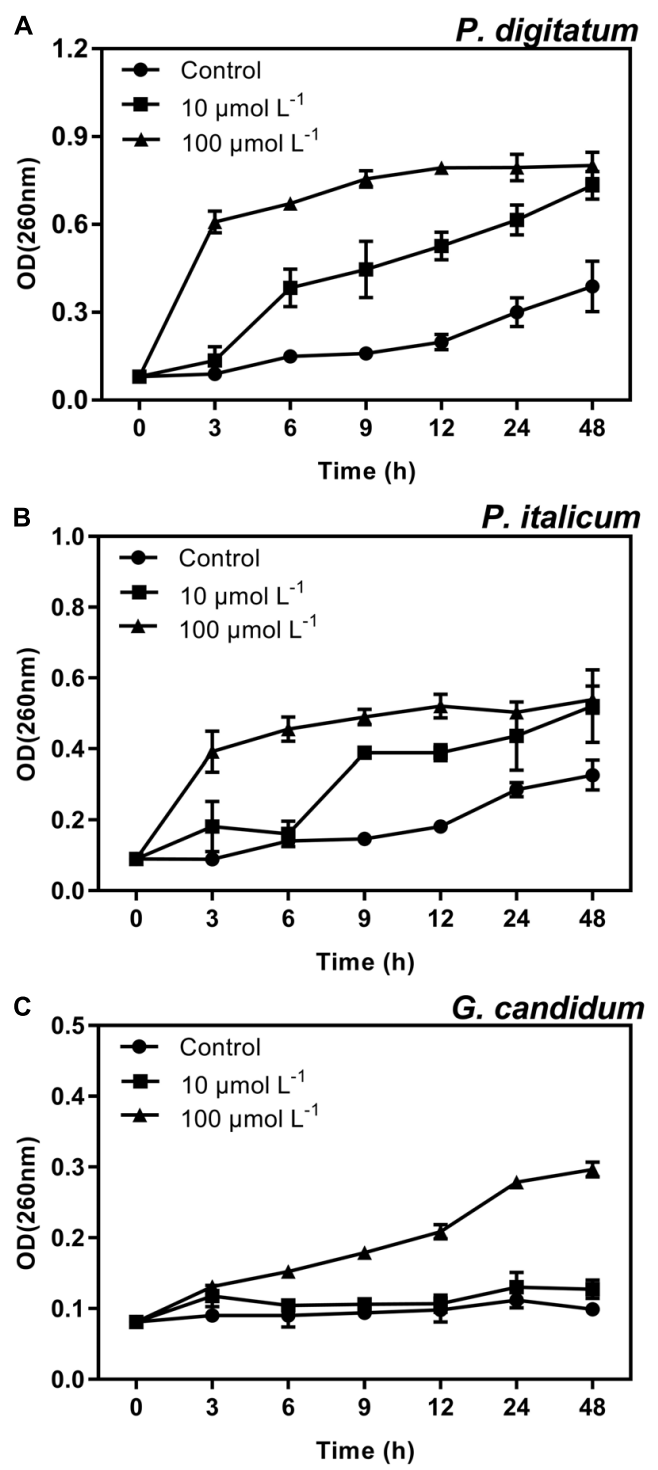

FIGURE 6 | Release of cellular constituents of $P$. digitatum (A), P. italicum (B), and $G$. candidum (C) mycelia treated with BP21. Mycelia were mixed with peptide BP21 at 10 or $100 \mu \mathrm{mol} \mathrm{L}{ }^{-1}$ or without BP21 (control) in phosphate buffered saline. Vertical bars indicate the standard error of the means.

entire experiment was conducted in triplicate. The data were analyzed via a one-way analysis of variance (ANOVA), followed by Duncan's multiple-range tests at $p<0.05$ (SPSS Statistics 22.0, Inc.).

\section{RESULTS}

\section{Growth Inhibition of the Fungi by BP21 in vitro}

The in vitro growth inhibition activities of the peptide BP21 were tested (Figure 1). The peptide BP21 showed the best inhibitory activity toward these three fungi. The MIC of BP21 against $P$. digitatum, $P$. italicum, and $G$. candidum was 8,8 , and $4 \mu \mathrm{mol} \mathrm{L}^{-1}$, respectively.

\section{Effect of BP21 on Morphological Alterations of Fungal Mycelia Analyzed Using Scanning Electron Microscopy (SEM)}

A SEM analysis was carried out to further visualize the effect of BP21 on the morphology of P. digitatum, P. italicum, and G. candidum mycelia, compared to control group (Figure 2). The control fungus without BP21 exhibited a regular and smooth surface (Figures 2A1,B1,C1). In contrast, $P$. digitatum, $P$. italicum, and $G$. candidum mycelia treated with BP21 (10 and $100 \mu \mathrm{mol} \mathrm{L}{ }^{-1}$ ) exhibited considerable changes in hyphal morphology. The mycelia treated with BP21 appeared to be severely collapsed due to leak. Mycelia became deformed, shrunken, and distorted (Figures 2A2,B2,C2,A3,B3,C3). Increasing concentrations of $\mathrm{BP} 21$ resulted in more serious damage.

\section{Effect of BP21 on the Permeation of Fungal Mycelia Analyzed Using Fluorescence Microscopy}

We used fluorescence microscopy and fluorescent dye SG to observe the mode of action of the mycelia with the peptide BP21. In controls in which mycelia was incubated with the SG probe without pretreatment with peptide BP21 $\left(0 \mu \mathrm{mol} \mathrm{L}^{-1}\right)$, no appreciable SG green fluorescent signal was discerned by using fluorescence microscopy (Figures 3B1,D1,F1). Mycelia exhibited slight discontinuous green fluorescence at $10 \mu \mathrm{mol} \mathrm{L}^{-1}$ BP21 (Figures 3B2,D2,F2). At this high BP21 concentration

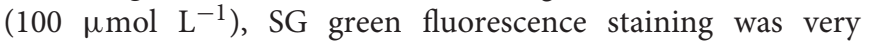
intense all along the $P$. digitatum and $P$. italicum mycelia (Figures 3B3,D3). G. candidum mycelia exposed to BP21 at $100 \mu \mathrm{mol} \mathrm{\textrm {L } ^ { - 1 }}$ exhibited discontinuous green fluorescent (Figure 3F3).

\section{The Effect of BP21 on Extracellular Conductivity of Fungal Mycelia}

Further antibacterial mode of action of peptide BP21 against the fungi was confirmed using the assay for the extracellular conductance (Figure 4). In this assay, the conductivity of all test groups increased gradually with increased treatment duration. The extracellular conductance sharply increased in the highconcentration $\left(100 \mu \mathrm{mol} \mathrm{L}^{-1}\right)$ BP21 treatment group $(p<0.05)$. According to the results, the peptide BP21 could increase the extracellular conductivity of $P$. digitatum, $P$. italicum, and G. candidum.

\section{Effect of BP21 on $\mathrm{K}^{+}$Efflux of Fungal Mycelia}

Potassium ions $\left(\mathrm{K}^{+}\right)$were found to leak from mycelia incubated with BP21 (Figure 5). BP21 significantly induced the release of $\mathrm{K}^{+}$, as the $\mathrm{K}^{+}$efflux of the high-concentration $\left(100 \mu \mathrm{mol} \mathrm{L}^{-1}\right)$ BP21 treatment group was significantly higher $(p<0.05)$ than 
TABLE 1 | Effects of BP21 on the fungal infection of citrus fruits.

\begin{tabular}{|c|c|c|c|c|c|c|c|}
\hline \multirow[t]{2}{*}{ Pathogen } & \multirow[t]{2}{*}{ Days } & \multicolumn{3}{|c|}{ DI (\%) } & \multicolumn{3}{|c|}{ LD (mm) } \\
\hline & & Control & A & B & Control & A & B \\
\hline \multirow[t]{3}{*}{ P. digitatum } & 3 & $70.00 \pm 10.00 \mathrm{a}$ & $6.67 \pm 5.77 b$ & $0.00 \pm 0.00 \mathrm{~b}$ & $18.57 \pm 2.23 a$ & $1.30 \pm 1.17 b$ & $0.00 \pm 0.00 \mathrm{~b}$ \\
\hline & 4 & $100.00 \pm 0.00 \mathrm{a}$ & $73.33 \pm 11.55 b$ & $3.33 \pm 5.77 c$ & $60.43 \pm 3.61 \mathrm{a}$ & $25.75 \pm 9.07 \mathrm{~b}$ & $1.42 \pm 2.45 c$ \\
\hline & 5 & $100.00 \pm 0.00 \mathrm{a}$ & $86.67 \pm 5.77 b$ & $3.33 \pm 5.77 c$ & $95.15 \pm 2.75 \mathrm{a}$ & $58.28 \pm 8.62 b$ & $2.67 \pm 4.62 \mathrm{c}$ \\
\hline \multirow[t]{3}{*}{ P. italicum } & 4 & $30.00 \pm 17.32 \mathrm{a}$ & $16.67 \pm 5.77 \mathrm{~b}$ & $0.00 \pm 0.00 \mathrm{c}$ & $5.32 \pm 1.50 \mathrm{a}$ & $2.92 \pm 0.88 b$ & $0.00 \pm 0.00 c$ \\
\hline & 5 & $79.17 \pm 8.78 \mathrm{a}$ & $70.00 \pm 10.00 a$ & $0.00 \pm 0.00 \mathrm{~b}$ & $20.04 \pm 0.83 a$ & $13.82 \pm 0.36 b$ & $0.00 \pm 0.00 c$ \\
\hline & 6 & $93.33 \pm 11.55 \mathrm{a}$ & $86.67 \pm 11.55 \mathrm{a}$ & $3.33 \pm 5.77 b$ & $33.24 \pm 3.35 \mathrm{a}$ & $26.00 \pm 0.98 b$ & $0.25 \pm 0.43 c$ \\
\hline \multirow[t]{3}{*}{ G. candidum } & 8 & $13.33 \pm 15.28 \mathrm{a}$ & $0.00 \pm 0.00 \mathrm{~b}$ & $0.00 \pm 0.00 \mathrm{~b}$ & $3.43 \pm 3.45 a$ & $0.00 \pm 0.00 \mathrm{~b}$ & $0.00 \pm 0.00 b$ \\
\hline & 10 & $16.67 \pm 11.55 \mathrm{a}$ & $0.00 \pm 0.00 \mathrm{~b}$ & $0.00 \pm 0.00 \mathrm{~b}$ & $6.80 \pm 2.22 \mathrm{a}$ & $0.00 \pm 0.00 \mathrm{~b}$ & $0.00 \pm 0.00 b$ \\
\hline & 12 & $16.67 \pm 11.55 \mathrm{a}$ & $0.00 \pm 0.00 \mathrm{~b}$ & $0.00 \pm 0.00 \mathrm{~b}$ & $9.81 \pm 4.29 \mathrm{a}$ & $0.00 \pm 0.00 \mathrm{~b}$ & $0.00 \pm 0.00 \mathrm{~b}$ \\
\hline
\end{tabular}

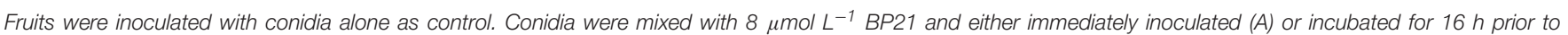

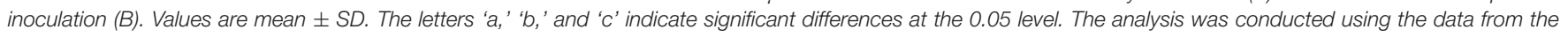
same pathogen on the same day.

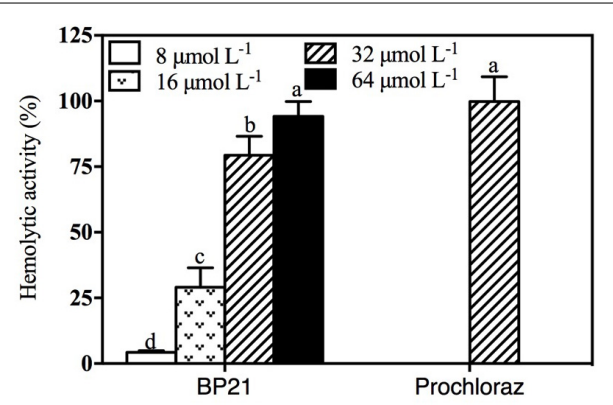

FIGURE 7 | Hemolytic activity of BP21. Release of hemoglobin was determined by the value of $\mathrm{OD}_{540}$. The hemolytic activity is given as the mean $\pm S D$ of the percentage of human erythrocyte hemolysis. Values followed by different letters are significantly different according to Duncan's multiple range test at $P<0.05$.

that of the control. Incubation with $10 \mu \mathrm{mol} \mathrm{L}{ }^{-1}$ BP21 did not result in a $\mathrm{K}^{+}$release significantly different from that of the control mycelia for $P$. italicum and $G$. candidum mycelia, but this concentration of BP21 did induce the release of $\mathrm{K}^{+}$from $P$. digitatum mycelia. Moreover, G. candidum mycelia incubated with $100 \mu \mathrm{mol} \mathrm{L}{ }^{-1}$ BP21 displayed significantly increased $\mathrm{K}^{+}$ release compared to the $10 \mu \mathrm{mol} \mathrm{L}^{-1} \mathrm{BP} 21$ treatment group and the control group.

\section{Effect of BP21 on the Release of Cellular Constituents of Fungal Mycelia}

Another strategy for determining the mode of action of BP21 against these three filamentous phytopathogenic was to analyze the release of $260 \mathrm{~nm}$ absorbing materials from the treated mycelia of $P$. digitatum, $P$. italicum, and G. candidum. The $\mathrm{OD}_{260}$ value of the culture filtrates of $P$. digitatum, $P$. italicum, and $G$. candidum mycelia exposed to BP21 revealed an increasing release of cellular constituents with respect to exposure time (Figure 6). However, the $\mathrm{OD}_{260}$ values of untreated (control) mycelia of $P$. digitatum and $P$. italicum increased slowly, and only slight changes in the $\mathrm{OD}_{260}$ value of the untreated (control) mycelia of $G$. candidum were observed. This finding directly confirms the release of cellular constituents from $P$. digitatum, $P$. italicum, and G. candidum treated with BP21.

\section{Effect of BP21 on P. digitatum, $P$. italicum, and G. candidum Infections on Citrus Fruit}

The inhibitory activity of the peptide BP21 against $P$. digitatum, $P$. italicum, and $G$. candidum infection was evaluated. The results showed that BP21 (treatment groups A and B) significantly inhibited citrus fruit diseases at $8 \mu \mathrm{mol} \mathrm{L}^{-1}$ compared to the nontreated controls $(p<0.05)$ (Table 1). Treatment B resulted in the most effective control of the three fungi growth on citrus fruit, wherein the growth of green mold and blue mold was reduced by $90 \%$ or more. Treatment A was more effective than the control treatment, but it was not as beneficial as treatment B. It turned out that the antifungal activity of BP21 increased along with time of incubation. In addition, BP21 completely controlled the G. candidum infection on citrus fruit, the LD and DI \% were 0 (A and B). This could be indicated that BP21 could also control infection in vivo.

\section{Hemolytic Activity of BP21}

Toxicity of different concentrations of BP21 to eukaryotic cells was determined by lysing human red blood cells (erythrocytes) (Figure 7). Prochloraz showed very high hemolytic activity, about 99.8\%. Low concentration of BP21 showed low hemolysis, the hemolysis activity of BP2 1 at $8 \mu \mathrm{mol} \mathrm{L}^{-1}$ was $4.30 \%$. However, the higher the concentration, the higher the hemolysis activity.

\section{DISCUSSION}

Blue mold and green mold are the primary post-harvest pathogen of citrus, and there is little effective control measures for sour rot; sour rot could be controlled by low-temperature environment, but chilling injury still causes major bottlenecks (Mercier and Smilanick, 2005). Therefore, exploration of effective methods for controlling these diseases have become urgently needed. 
Currently, the post-harvest application of short synthetic AMPs is an attractive alternative to fungicides (López-García et al., 2002).

In the present study, BP21 was shown to effectively inhibit the growth of $P$. digitatum, P. italicum, and G. candidum in vitro. When the concentration of BP21 was $8 \mu \mathrm{mol} \mathrm{L}{ }^{-1}$, these fungi could not grow (Figure 1). The results of the SEM analysis clearly showed the difference between the treated and untreated fungi mycelia. The mycelia treated with BP21 became shrunken, collapsed, distorted, and formed a rough surface (Figure 2). This effect on the cell membranes of pathogens is similar to the effect of several essential oils (Helal et al., 2007; Bajpai et al., 2013) and citral (Tao et al., 2014). The effect may be attributed to the leakage of intracellular constituents. The cell membrane plays an important role in cell life activities, and cell membrane breakage causes the leakage of small molecular substances and ions. SG signals showed that BP21 could change the membrane permeability (Figure 3). The SG signals were more strong at higher concentration groups than at lower concentration groups. The increase in BP21 concentration resulted in a concomitant increase in the damage to the cell membrane. This mode is very similar to many of the cationic AMPs, such as some PAFs (Harries et al., 2013; López-García et al., 2015) and tetralipopeptides (Makovitzki et al., 2006), their mode of action involves permeation and disintegration of membranes. Membrane permeability parameters, including extracellular conductivity (Figure 4), leakage of potassium ions (Figure 5), and release of cellular constituents (Figure 6), were used to indicate gross and irreversible damage to the cytoplasmic and membranes (Bajpai et al., 2013). These parameters visibly increased as the concentration of BP21 increased. Although, hemolytic activity was positively correlated with the concentration of BP21 (Figure 7). After systematic toxicity evaluation in future research, BP2 1 could also be used at lower concentrations or be modified to reduce its hemolysis.

The peptide BP21 was shown to effectively control of $P$. digitatum, $P$. italicum, and G. candidum infection in citrus fruits in vivo (Table 1). Conidia were incubated with BP21 at a single concentration $\left(8 \mu \mathrm{mol} \mathrm{L}{ }^{-1}\right)$ for $0 \mathrm{~h}$ (treatment $\mathrm{A}$ ) or $16 \mathrm{~h}$ (treatment $\mathrm{B}$ ) before inoculation. Treatment $\mathrm{B}$ resulted in the

\section{REFERENCES}

Alberola, J., Rodriguez, A., Francino, O., Roura, X., Rivas, L., and Andreu, D. (2004). Safety and efficacy of antimicrobial peptides against naturally acquired leishmaniasis. Antimicrob. Agents Chemother. 48, 641-643. doi: 10.1128/AAC. 48.2.641-643.2004

Andreu, D., Merrifield, R. B., Steiner, H., and Boman, H. G. (1983). Solid-phase synthesis of cecropin A and related peptides. Proc. Natl. Acad. Sci. U.S.A. 80, 6475-6479. doi: 10.1073/pnas.80.21.6475

Badosa, E., Ferré, R., Francés, J., Bardají, E., Feliu, L., Planas, M., et al. (2009). Sporicidal activity of synthetic antifungal undecapeptides and control of Penicillium rot of apples. Appl. Environ. Microbiol. 75, 5563-5569. doi: 10.1128/ AEM.00711-09

Bajpai, V. K., Sharma, A., and Baek, K. H. (2013). Antibacterial mode of action of Cudrania tricuspidata fruit essential oil, affecting membrane permeability and surface characteristics of food-borne pathogens. Food Control 32, 582-590. doi: 10.1016/j.foodcont.2013.01.032

Chicharro, C., Granata, C., Lozano, R., Andreu, D., and Rivas, L. (2001). $\mathrm{N}$-terminal fatty acid substitution increases the leishmanicidal activity of best performance of control of fungi infect and growth on fruits. Treatment A was more effective than the control treatment, but it was not as effective as treatment B. Obviously, in treatment B, the BP21 had more time to interact with the conidia, thus resulting in better disease control. This finding suggests that BP21 could be applied in production by soaking the fruits in a BP21 solution for a short duration. More research on the most effective method is warranted.

\section{CONCLUSION}

The results of this study have shown that BP21 could effectively control infectious fungal diseases of citrus fruits, and it underlines the potential utility of BP21 as a novel broad-spectrum fungicide against pathogens of citrus as well. The major challenge of the widespread use of peptides for food and agriculture is to meet the requirement of a low production cost. Therefore, it is necessary to find or design peptides with no or little toxicity that control bacteria and fungi even when applied at low concentrations.

\section{AUTHOR CONTRIBUTIONS}

KZ conceived and supervised the project. WW and SL designed the experiments and performed most of the experiments. WW analyzed the data and wrote the manuscript. LD, SY, and JM gave advice and edited the manuscript. All authors read and approved the final manuscript.

\section{FUNDING}

This research was supported by the Technology Innovation Fund of Chongqing (Grant No. cstc2016shms-ztzx80005), the Key Project in Applied Technology of Chongqing Science and Technology Commission (Grant No. cstc2017shms-xdny80058), and the Fundamental Research Funds for the Central Universities (Grant No. XDJK2017D132).

CA (1-7) M (2-9), a cecropin-melittin hybrid peptide. Antimicrob. Agents Chemother. 45, 2441-2449. doi: 10.1128/AAC.45.9.2441-2449.2001

Ciociola, T., Giovati, L., Conti, S., Magliani, W., Santinoli, C., and Polonelli, L. (2016). Natural and synthetic peptides with antifungal activity. Future Med. Chem. 8, 1413-1433. doi: 10.4155/fmc-2016-0035

Droby, S., Vinoku, V., Weiss, B., Cohen, L., Daus, A., Goldschmidt, E. E., et al. (2002). Induction of resistance to Penicillium digitatum in grapefruit by the yeast biocontrol agent Candida oleophila. Phytopathology 92, 393-399. doi: 10.1094/PHYTO.2002.92.4.393

Ferre, R., Badosa, E., Feliu, L., Planas, M., Montesinos, E., and Bardaji, E. (2006). Inhibition of plant-pathogenic bacteria by short synthetic cecropin A-melittin hybrid peptides. Appl. Environ. Microbiol. 72, 3302-3308. doi: 10.1128/AEM. 72.5.3302-3308.2006

Ferre, R., Melo, M. N., Correia, A. D., Feliu, L., Bardají, E., Planas, M., et al. (2009). Synergistic effects of the membrane actions of cecropin-melittin antimicrobial hybrid peptide BP100. Biophys. J. 96, 1815-1827. doi: 10.1016/j.bpj.2008. 11.053

Harries, E., Carmona, L., Muñoz, A., Ibeas, J. I., Read, N. D., Gandía, M., et al. (2013). Genes involved in protein glycosylation determine the activity and cell 
internalization of the antifungal peptide PAF26 in Saccharomyces cerevisiae. Fungal Genet. Biol. 58, 105-115. doi: 10.1016/j.fgb.2013.08.004

Helal, G. A., Sarhan, M. M., Abu Shahla, A. N. K., and Abou El-Khair, E. K. (2007). Effects of Cymbopogon citratus L. essential oil on the growth, morphogenesis and aflatoxin production of Aspergillus flavus ML2-strain. J. Basic Microbiol. 47, 5-15. doi: 10.1002/jobm.200610137

Ismail, M., and Zhang, J. (2004). Post-harvest citrus diseases and their control. Outlooks Pest Manage. 15, 29-35. doi: 10.1564/15feb12

Jenssen, H., Hamill, P., and Hancock, R. E. (2006). Peptide antimicrobial agents. Clin. Microbiol. Rev. 19, 491-511. doi: 10.1128/CMR.000 56-05

Jeong, R. D., Chu, E. H., Lee, G. W., Cho, C., and Park, H. J. (2016). Inhibitory effect of gamma irradiation and its application for control of postharvest green mold decay of Satsuma mandarins. Int. J. Food Microbial. 234, 1-8. doi: 10.1016/j. ijfoodmicro.2016.06.026

Keymanesh, K., Soltani, S., and Sardari, S. (2009). Application of antimicrobial peptides in agriculture and food industry. World J. Microbiol. Biotechnol. 25, 933-944. doi: 10.1007/s11274-009-9984-7

López-García, B., Harries, E., Carmona, L., Campos-Soriano, L., López, J. J., Manzanares, P., et al. (2015). Concatemerization increases the inhibitory activity of short, cell-penetrating, cationic and tryptophan-rich antifungal peptides. Appl. Microbiol. Biotechnol. 99, 8011-8021. doi: 10.1007/s00253-0156541-1

López-García, B., Pérez-Payá, E., and Marcos, J. F. (2002). Identification of novel hexapeptides bioactive against phytopathogenic fungi through screening of a synthetic peptide combinatorial library. Appl. Environ. Microbiol. 68, 24532460. doi: 10.1128/AEM.68.5.2453-2460.2002

Makovitzki, A., Avrahami, D., and Shai, Y. (2006). Ultrashort antibacterial and antifungal lipopeptides. Proc. Natl. Acad. Sci. U.S.A. 103, 15997-16002. doi: 10.1073/pnas.0606129103

Makovitzki, A., Viterbo, A., Brotman, Y., Chet, I., and Shai, Y. (2007). Inhibition of fungal and bacterial plant pathogens in vitro and in planta with ultrashort cationic lipopeptides. Appl. Environ. Microbiol. 73, 6629-6636. doi: 10.1128/ AEM.01334-07

Mercier, J., and Smilanick, J. L. (2005). Control of green mold and sour rot of stored lemon by biofumigation with Muscodor albus. Biol. Control 32, 401-407. doi: 10.1016/j.biocontrol.2004.12.002

Muñoz, A., López-García, B., and Marcos, J. F. (2006). Studies on the mode of action of the antifungal hexapeptide PAF26. Antimicrob. Agents Chemother. 50, 3847-3855. doi: 10.1128/AAC.00650-06
Muñoz, A., López-García, B., and Marcos, J. F. (2007). Comparative study of antimicrobial peptides to control citrus postharvest decay caused by Penicillium digitatum. J. Agric. Food Chem. 55, 8170-8176. doi: 10.1021/jf0718143

Paul, S., Dubey, R. C., Maheswari, D. K., and Kang, S. C. (2011). Trachyspermum ammi (L.) fruit essential oil influencing on membrane permeability and surface characteristics in inhibiting food-borne pathogens. Food Control 22, 725-731. doi: 10.1016/j.foodcont.2010.11.003

Puig, M., Moragrega, C., Ruz, L., Calderón, C. E., Cazorla, F. M., Montesinos, E., et al. (2016). Interaction of antifungal peptide BP15 with Stemphylium vesicarium, the causal agent of brown spot of pear. Fungal Biol. 120, 61-71. doi: 10.1016/j.funbio.2015.10.007

Puig, M., Moragrega, C., Ruz, L., Montesinos, E., and Llorente, I. (2014). Postinfection activity of synthetic antimicrobial peptides against, Stemphylium vesicarium in pear. Phytopathology 104, 1192-1200. doi: 10.1094/PHYTO-0214-0036-R

Romanazzi, G., Feliziani, E., Baños, S. B., and Sivakumar, D. (2017). Shelf life extension of fresh fruit and vegetables by chitosan treatment. Crit. Rev. Food Sci. Nutr. 57, 579-601. doi: 10.1080/10408398.2014.900474

Schirra, M., D'Aquino, S., Cabras, P., and Angioni, A. (2011). Control of postharvest diseases of fruit by heat and fungicides: efficacy, residue levels, and residue persistence. A review. J. Agric. Food Chem. 59, 8531-8542. doi: $10.1021 / \mathrm{jf} 201899 \mathrm{t}$

Tao, N., OuYang, Q., and Jia, L. (2014). Citral inhibits mycelial growth of Penicillium italicum by a membrane damage mechanism. Food Control 41, 116-121. doi: 10.1016/j.foodcont.2014.01.010

Wang, W., Deng, L., Yao, S., and Zeng, K. (2018). Control of green and blue mold and sour rot in citrus fruits by the cationic antimicrobial peptide PAF56. Postharvest Biol. Technol. 136, 132-138. doi: 10.1016/j.postharvbio.2017.10.015

Conflict of Interest Statement: The authors declare that the research was conducted in the absence of any commercial or financial relationships that could be construed as a potential conflict of interest.

Copyright (c) 2018 Wang, Liu, Deng, Ming, Yao and Zeng. This is an open-access article distributed under the terms of the Creative Commons Attribution License (CC BY). The use, distribution or reproduction in other forums is permitted, provided the original author(s) and the copyright owner(s) are credited and that the original publication in this journal is cited, in accordance with accepted academic practice. No use, distribution or reproduction is permitted which does not comply with these terms. 